\title{
Reduced Graphene Oxide as a Monolithic Multifunctional Conductive Binder for Activated Carbon Supercapacitors
}

\author{
Dona T. L. Galhena, ${ }^{* \dagger}{ }^{\dagger}$ Bernhard C. Bayer, ${ }^{\ddagger},{ }_{(1)}$ Jannik C. Meyer, ${ }^{\ddagger}$ Stephan Hofmann, ${ }^{\dagger}$ \\ and Gehan A. J. Amaratunga ${ }^{\dagger}$ \\ ${ }^{\dagger}$ Electrical Engineering Division, Department of Engineering, University of Cambridge, 9 J. J. Thomson Avenue, CB3 0FA \\ Cambridge, U.K. \\ ${ }^{\ddagger}$ Faculty of Physics, University of Vienna, Boltzmanngasse 5, A-1090 Vienna, Austria \\ ${ }^{\S}$ Institute of Materials Chemistry, Vienna University of Technology (TU Wien), Getreidemarkt 9/165, A-1060 Vienna, Austria
}

\section{Supporting Information}

\begin{abstract}
Using reduced graphene oxide ( $r-\mathrm{GO}$ ) as a multifunctional conductive binder, a simple, cost-effective, and environmentally friendly approach is developed to fabricate activated carbon/reduced graphene oxide $(\mathrm{AC} / \mathrm{r}-\mathrm{GO})$ composite electrodes for supercapacitors with outstanding performance. In such a composite, r-GO provides several much needed critical functions: r-GO not only serves as the binder material improving the AC particle/particle cohesion and electrode-film/substrate adhesion but also improves the electrical conductivity of the composite and provides additional surfaces for ion adsorption. Furthermore, during electrode fabrication, initial GO precursor functions as an effective dispersant for $\mathrm{AC}$, resulting in a stable electrode material slurry. Employing characterization by advanced microscopy techniques, we show that $\mathrm{AC}$ and $\mathrm{r}-\mathrm{GO}$

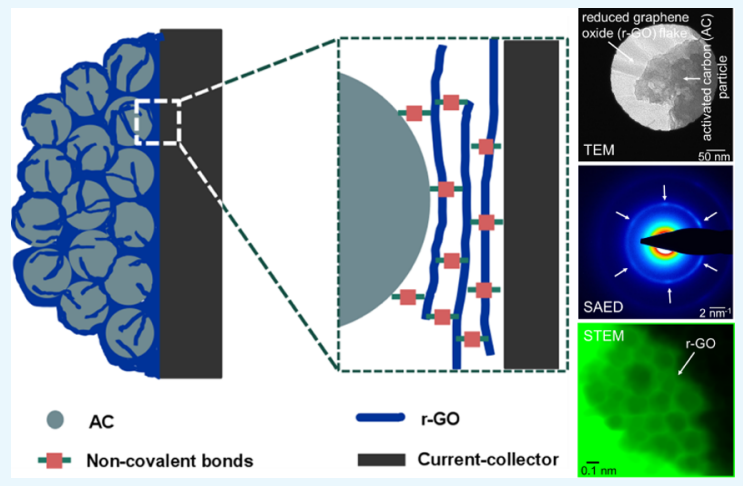
assemble into an interconnected network structure, resulting in a composite with high specific capacitance, excellent rate capability, and long cycling life stability. Such high-performance electrodes coupled with their relatively simple, scalable, and low-cost fabrication process thereby provide a clear pathway toward large-scale implementation of supercapacitors.
\end{abstract}

\section{INTRODUCTION}

One of the key challenges in the 21 st century is unquestionably energy storage, where electrochemical double-layer capacitors (EDLCs), also called supercapacitors or ultracapacitors, offer a promising, low-cost, reliable, and environmentally friendly solution. Supercapacitors feature fast charge-discharge capability, long lifecycles, a wide range of operating temperatures, and operational safety and represent an emerging class of power sources for portable electronic devices. ${ }^{1}$ As the range of applications of supercapacitors spans from digital cameras, mobile phones, to hybrid vehicles, improving their performance, especially the energy density while maintaining the high power density and cycling stability, remains a primary research focus in the field. Because electrode materials are the key components to the performance of supercapacitors, rationally designing and fabricating high-quality electrode materials play a decisive role in developing next-generation high-performance supercapacitors. $^{2-4}$

In the industrial cell-manufacturing processes, supercapacitor electrodes are cast onto a current collector from slurries that contain the active electrode material. Today, virtually all industrial supercapacitor manufacturers use coconut shellderived activated carbon (AC) as the active electrode material due to its high surface area and porosity, stability during cycling, and low cost. ${ }^{5}$ However, AC alone cannot maintain the required electrical conductivity and mechanical stability of the electrode, and hence electrode slurries generally are also added to the binder system, which maintains both electrical and mechanical integrity of the electrodes once casted on to the current collector. Traditional binder systems are dualcomponent based, typically a polymer binder and a conductive additive, for two different functionalities. The organic polymer binder, such as poly(vinylidene fluoride) (PVDF), ${ }^{6,7}$ poly(tetrafluoroethylene) (PTFE), ${ }^{8-10}$ and carboxy methyl cellulose (CMC), ${ }^{11-13}$ is used to maintain the cohesion between $\mathrm{AC}$ particles and the adhesion of electrode film to the current collector. Conductive additives, such as carbon black (CB), are added to improve the conductivity of the electrode and hence the high rate performance of the supercapacitor. However, the organic polymer binders, themselves, are nonconductive and electrochemically inert, thus making no contribution to the total capacitance of the device. Therefore, they not only

Received: $\quad$ May 21, 2018

Accepted: August 7, 2018

Published: August 16, 2018 
(a)

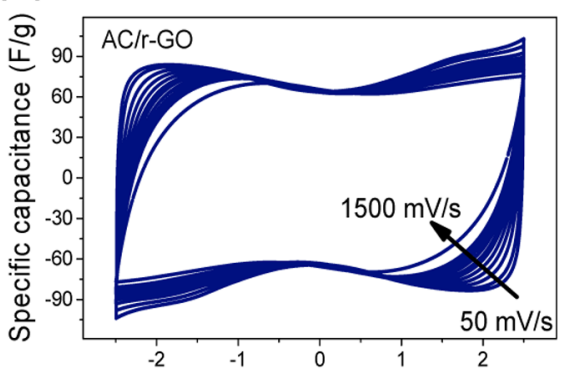

(d)

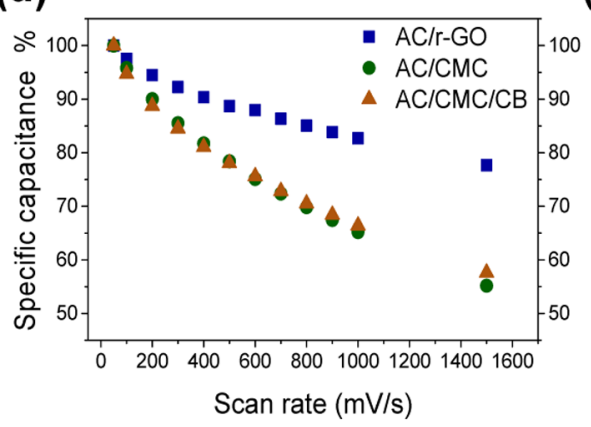

(g)

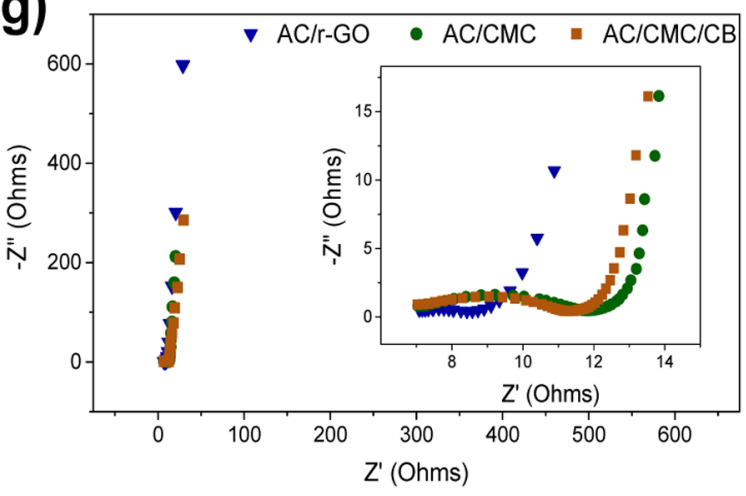

(b)

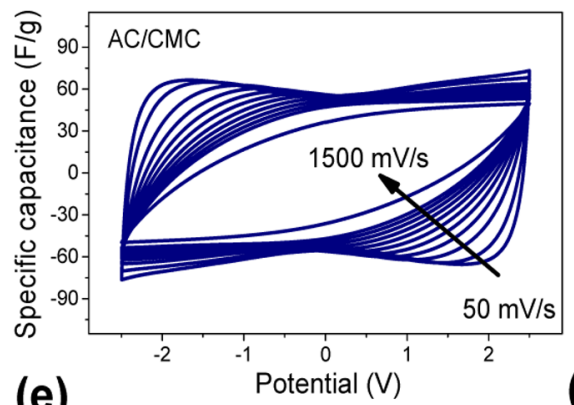

(e)

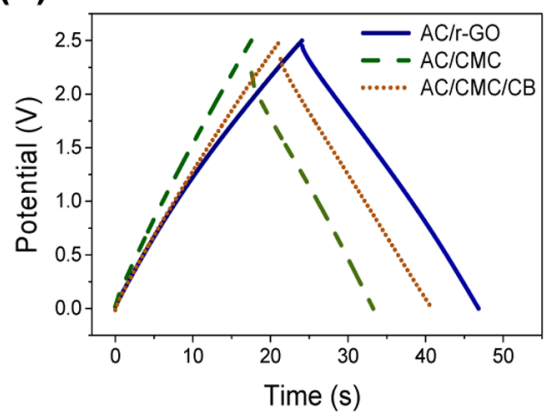

(c)

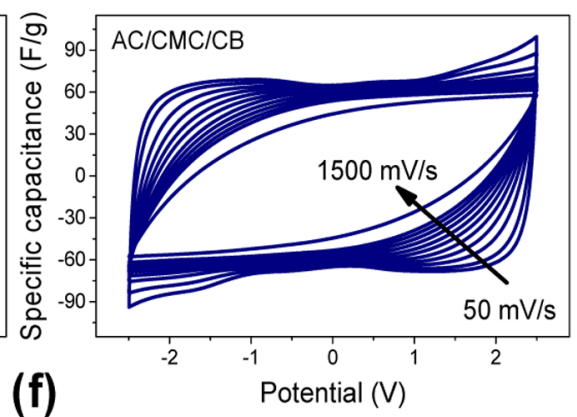

(f)

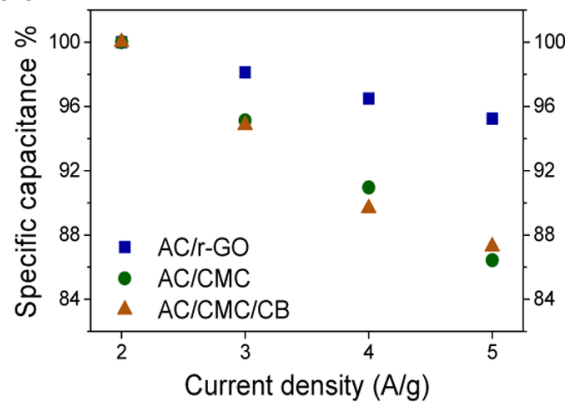

(h)

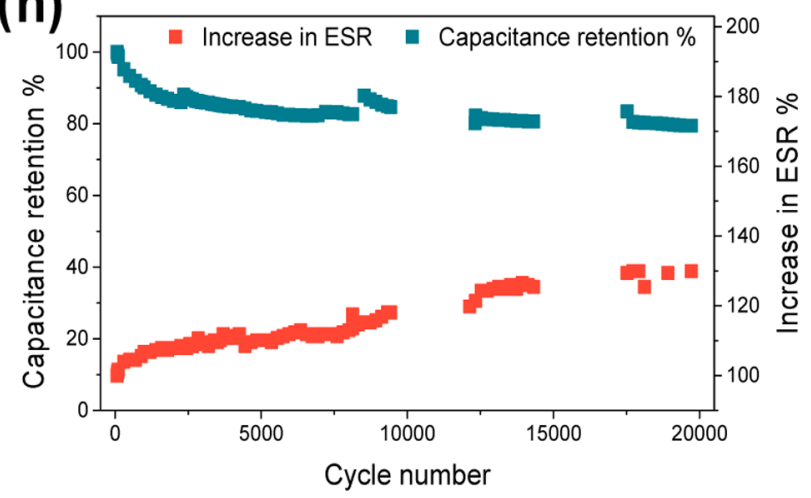

Figure 1. Evaluation of the electrochemical performance of AC/r-GO supercapacitor and comparative supercapacitors; $\mathrm{AC} / \mathrm{CMC}$ and $\mathrm{AC} / \mathrm{CMC} /$ $\mathrm{CB}$; in $\mathrm{TEABF}_{4} / \mathrm{PC}$ electrolyte solution. (a) Cyclic voltammograms for the AC/r-GO supercapacitor (b) AC/CMC supercapacitor, (c) AC/ $\mathrm{CMC} / \mathrm{CB}$ supercapacitor cycled between -2.5 and $+2.5 \mathrm{~V}$ at scan rates 50,100, 200, 300, 400, 500, 600, 700, 800, 900, 1000, and 1500 mV/s. (d) Variation in the specific capacitance with the scan rate for AC/r-GO, AC/CMC, and AC/CMC/CB. The specific capacitance of each device at different scan rates is given as a percentage of specific capacitance of that device at $50 \mathrm{mV} / \mathrm{s}$. (e) Galvanostatic charge-discharge curves at a current density of $2 \mathrm{~A} / \mathrm{g}$. (f) Comparison of specific capacitances at different current densities for the $\mathrm{AC} / \mathrm{r}-\mathrm{GO}, \mathrm{AC} / \mathrm{CMC}$, and $\mathrm{AC} / \mathrm{CMC} / \mathrm{CB}$ supercapacitors. The specific capacitance of each device at different current densities is given as a percentage of specific capacitance of that device at $2 \mathrm{~A} / \mathrm{g}$. (g) Nyquist plots for the AC/r-GO, AC/CMC, and AC/CMC/CB supercapacitors using a sinusoidal signal of $10 \mathrm{mV}$ over the frequency range from 0.01 to $100000 \mathrm{~Hz}$, with their expanded views of the high-frequency region in the inset. (h) Cycling stability and evolution of the equivalent series resistance (ESR) of $\mathrm{AC} / \mathrm{r}-\mathrm{GO}$ electrochemical capacitor: the capacity retention rate (normalized to the initial capacitance) and increase in ESR (normalized to the initial ESR) for 20000 cycles of charge-discharge tests.

increase the electrical resistance of the electrode but also increase the "dead" weight of the electrode, which ultimately reduces the overall energy and power densities of the supercapacitor. Furthermore, in realizing greener processes for electrode fabrication, there is a need for replacing fluorinecontaining binders such as PVDF and PTFE due to their environmental impact. ${ }^{14,15}$ On the other hand, addition of conductive additives, such as carbon black, may partly alleviate the problem of electrical conduction but can only establish electrical connection through a percolating point-to-point contact and also decreases the tensile strength and extensibility of the binders. ${ }^{7}$ Based on the above facts, an ideal binder material should be adhesive, electrically conductive, light, electrochemically active, and additionally form stable electrode slurries.

Although the role of the binder system is as important as that of the active material itself, in supercapacitor research, binders have received the least attention to date. Although several studies have tried to overcome the drawbacks of the binder systems by preparing binder-free self-standing thin film $^{16-26}$ or aerogel electrodes, ${ }^{27-29}$ they are only compatible to an limited extent with large-scale electrode fabrication in industrial supercapacitor manufacturing processes. ${ }^{15}$ In contrast, the development of a monolithic binder material that intrinsically combines electrical conductivity and mechanical integrity by holding AC particles together and further bonding the electrode film to the current collector, while itself also 
acting as an electrochemically active double-layer material, remains strongly underdeveloped in the literature. ${ }^{30-32}$

Addressing the aforementioned issues, herein we present a rational method to fabricate AC-based supercapacitor electrodes, in which we introduce reduced graphene oxide ( $r-G O)$ as a highly efficient, monolithic, conductive binder material, which holds individual AC particles into a compact electrode layer adhered on to the current collector. Our approach synergistically combines mechanical integrity with good electrical conduction between AC particles, with the added benefit that $\mathrm{r}-\mathrm{GO}$ also additionally serves as an active electrochemical double-layer material itself, thus circumventing a dead weight effect. Thereby, r-GO as a binder in AC supercapacitor electrodes enables much enhanced capacitance performance, rate capability, and cycling life stability compared to conventional dual-component organic polymer/conductive additive binder systems. Importantly, we link this enhanced performance to a comprehensive materials characterization of our novel $\mathrm{AC} / \mathrm{r}-\mathrm{GO}$ composite electrodes, thus developing an extendible framework toward optimization of multifunctional monolithic binders for supercapacitors.

\section{RESULTS}

For the preparation of the electrode material layer composed of $\mathrm{r}-\mathrm{GO}$ and $\mathrm{AC}$ particles, a commercially available supercapacitor grade coconut shell AC (YP-50F from Kuraray Chemicals) was used. Graphene oxide (GO), synthesized by oxidizing vein graphite following Hummer's method, ${ }^{33}$ was used as the starting material of the r-GO. A well-dispersed mixture of $\mathrm{GO}$ and $\mathrm{AC}$ in propylene carbonate (PC) was coated onto the $\mathrm{Al}$ current collector and GO within the electrode material was converted into r-GO by low-temperature thermal reduction. The initial ratio of $\mathrm{GO}$ to $\mathrm{AC}$ was set to $1: 10$ by weight. Weight ratio of $\mathrm{r}-\mathrm{GO}$ to $\mathrm{AC}$ in the electrode layer obtained after the electrode layer is applied on to the current collector and the reduction is performed is about $0.65: 10$ by weight. This is because the weight of the starting GO is reduced by about $35 \%$ (from thermogravimetric analysis of GO) during the reduction of the graphene oxide due to the removal of oxide groups. ${ }^{2,34,35}$ Other weight ratios of GO to AC examined were 10:1, 1:1, and 1:20. For 10:1 and 1:1 weight ratios, the electrochemical performance of the resulting supercapacitors was lower than that for 1:10 weight ratio. For $1: 20$, the binding between the current collector and the electrode layer and binding between $\mathrm{AC}$ particles were poor.

To evaluate the electrochemical performance of $\mathrm{AC} / \mathrm{r}-\mathrm{GO}$ composite electrodes, symmetric two-electrode supercapacitors were fabricated with tetraethylammonium tetrafluoroborate $\left(\mathrm{TEABF}_{4}\right)$ dissolved in $\mathrm{PC}$ as the electrolyte (referred as AC/ r-GO supercapacitor). To facilitate direct comparisons, two comparative reference supercapacitors were prepared with electrodes composed of (a) a conventional organic binder, sodium carboxy methyl cellulose (CMC), with AC (1:10), referred to as $\mathrm{AC} / \mathrm{CMC}$, and (b) the conventional dualcomponent binder system $\mathrm{CMC}$ and carbon black $(\mathrm{CB})$ with AC (1:1:10), referred to as $\mathrm{AC} / \mathrm{CMC} / \mathrm{CB}$. For details on materials and methods see the Supporting Information. For further comparisons, the electrochemical performance of a supercapacitor prepared with pure r-GO measured under the same conditions is also given in the Supporting Information (referred to as $\mathrm{r}-\mathrm{GO}$ supercapacitor) (Supporting Information Figure 1).
Figure 1a shows the cyclic voltammograms (CV) for the $\mathrm{AC} / \mathrm{r}-\mathrm{GO}$ supercapacitor cycled between -2.5 and $+2.5 \mathrm{~V}$ at scan rates 50, 100, 200, 300, 400, 500, 600, 700, 800, 900, 1000 , and $1500 \mathrm{mV} / \mathrm{s}$. Near-rectangular CV curves at all scan rates from 50 to $1500 \mathrm{mV} / \mathrm{s}$ with no major pseudocapacitance contribution indicate the ideal double-layer capacitor behavior (also see Supporting Information Figure 2). Additionally, the $\mathrm{AC} / \mathrm{r}-\mathrm{GO}$ electrode is robust enough to be charged and discharged over a wide range of scan rates $(50-1500 \mathrm{mV} / \mathrm{s}$ ) and still maintains its nearly ideal rectangular CV shape. Based on the area of the $\mathrm{CV}$ curve, we calculated the specific capacitance of the $\mathrm{AC} / \mathrm{r}-\mathrm{GO}$ supercapacitor as $77.6 \mathrm{~F} / \mathrm{g}$ at 50 $\mathrm{mV} / \mathrm{s}$, and as the scan rate increases to $1500 \mathrm{mV} / \mathrm{s}$, it retains $60.3 \mathrm{~F} / \mathrm{g}$ with a capacitance retention ratio of $78 \%$ (Figure $1 \mathrm{~d}$ ). In contrast, the comparative supercapacitors exhibit lower specific capacitances of $60.3 \mathrm{~F} / \mathrm{g}$ (AC/CMC) (Figure $1 \mathrm{~b}$ ) and $68.9 \mathrm{~F} / \mathrm{g}(\mathrm{AC} / \mathrm{CMC} / \mathrm{CB}$ ) (Figure 1c) at $50 \mathrm{mV} / \mathrm{s}$ with capacitance retention ratio of only 55 and $58 \%$, respectively, at $1500 \mathrm{mV} / \mathrm{s}$ (Figure 1d). Markedly distorted CV curves of AC/ $\mathrm{CMC}$ (Figure 1b) and $\mathrm{AC} / \mathrm{CMC} / \mathrm{CB}$ (Figure 1c) supercapacitors at higher scan rates are a further evidence of their poorer rate capability.

Galvanostatic charge-discharge measurements at varying current densities further illustrate the excellent rate performance of the AC/r-GO electrodes. The specific capacitance, at 2 $\mathrm{A} / \mathrm{g}$, was estimated as $79.8 \mathrm{~F} / \mathrm{g}$ for the $\mathrm{AC} / \mathrm{r}-\mathrm{GO}$ supercapacitor and is thereby higher than $57.5 \mathrm{~F} / \mathrm{g}$ for the $\mathrm{AC} /$ $\mathrm{CMC}$ and $66.0 \mathrm{~F} / \mathrm{g}$ for the $\mathrm{AC} / \mathrm{CMC} / \mathrm{CB}$ supercapacitors (Figure $1 \mathrm{e})$. In addition, the sharp response and a small voltage drop $(0.048 \mathrm{~V})$ at the start of the discharge curve are indicative of the formation of an efficient EDL and fast ion transport within the $\mathrm{AC} / \mathrm{r}-\mathrm{GO}$ electrodes. The linear time dependence of the potential suggests the absence of major Faradic processes due to functional groups remaining on $\mathrm{r}-\mathrm{GO}$. As the current density increases from 2 to $5 \mathrm{~A} / \mathrm{g}$, the $\mathrm{AC} / \mathrm{r}-\mathrm{GO}$ supercapacitor consistently exhibits a higher specific capacitance and shows little change $(4.8 \%)$ with increase in operating power compared to significant drop in the performance of the comparative counterparts (13.6 and $12.8 \%$ for $\mathrm{AC} / \mathrm{CMC}$ and $\mathrm{AC} / \mathrm{CMC} / \mathrm{CB}$, respectively) (Figure 1f).

The facilitated ion transport within the $\mathrm{AC} / \mathrm{r}-\mathrm{GO}$ electrodes can also be confirmed from the electrochemical impedance spectra (EIS). A complex plan plot of the impedance data of $\mathrm{AC} / \mathrm{r}-\mathrm{GO}$ along with comparative cells is shown in Figure $1 \mathrm{~g}$ over the frequency range from 0.01 to $100000 \mathrm{~Hz}$. An expanded view of the high-frequency region is provided in the inset. The $\mathrm{AC} / \mathrm{r}-\mathrm{GO}$ supercapacitor gives the smallest highfrequency semicircle, indicating the smallest electrodeelectrolyte charge transfer resistance. The small charge transfer resistance indicates a very fast charge-transport rate, which is in good agreement with $\mathrm{CV}$ and high current charge-discharge studies. $^{36}$

Furthermore, AC/r-GO also demonstrated excellent cycling stability with $\sim 80 \%$ capacitance retention over 20000 chargedischarge cycles (Figure $1 \mathrm{~h}$ ), indicating a robust architecture of the electrode material. At the same time, ESR slowly increases during cycling. ${ }^{37}$

The electrochemical characterization results have shown excellent electrochemical response of the $\mathrm{AC} / \mathrm{r}-\mathrm{GO}$ electrodes compared to the comparative electrodes in terms of chargedischarge capacity, rate capability, and cyclic performance. To link this superior electrochemical performance of the novel $\mathrm{AC} / \mathrm{r}-\mathrm{GO}$ composite with its nano- and microstructure, the 

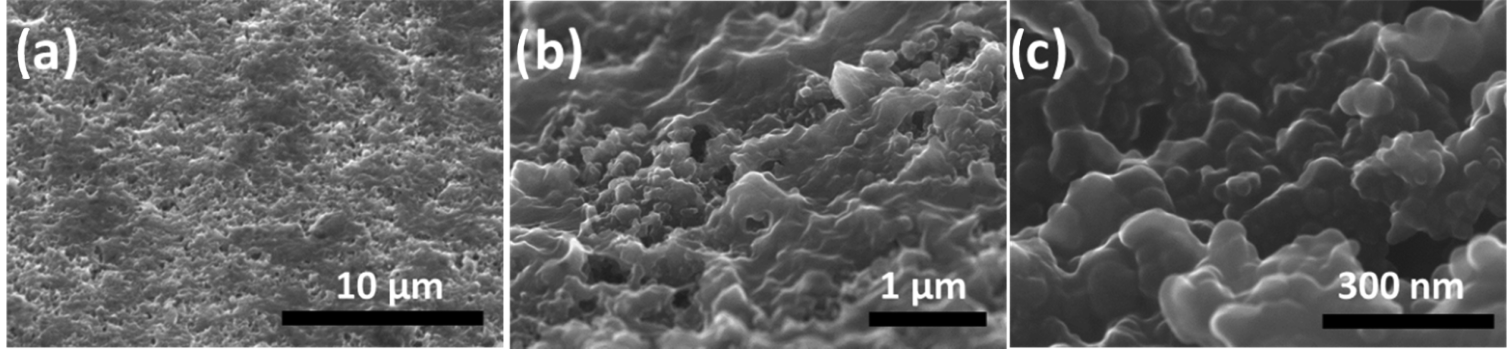

Figure 2. SEM images of the AC/r-GO electrode material at different magnifications, (a) $10 \mu \mathrm{m}$, (b) $1 \mu \mathrm{m}$, and (c) $300 \mathrm{~nm} \mathrm{scalebars}$.
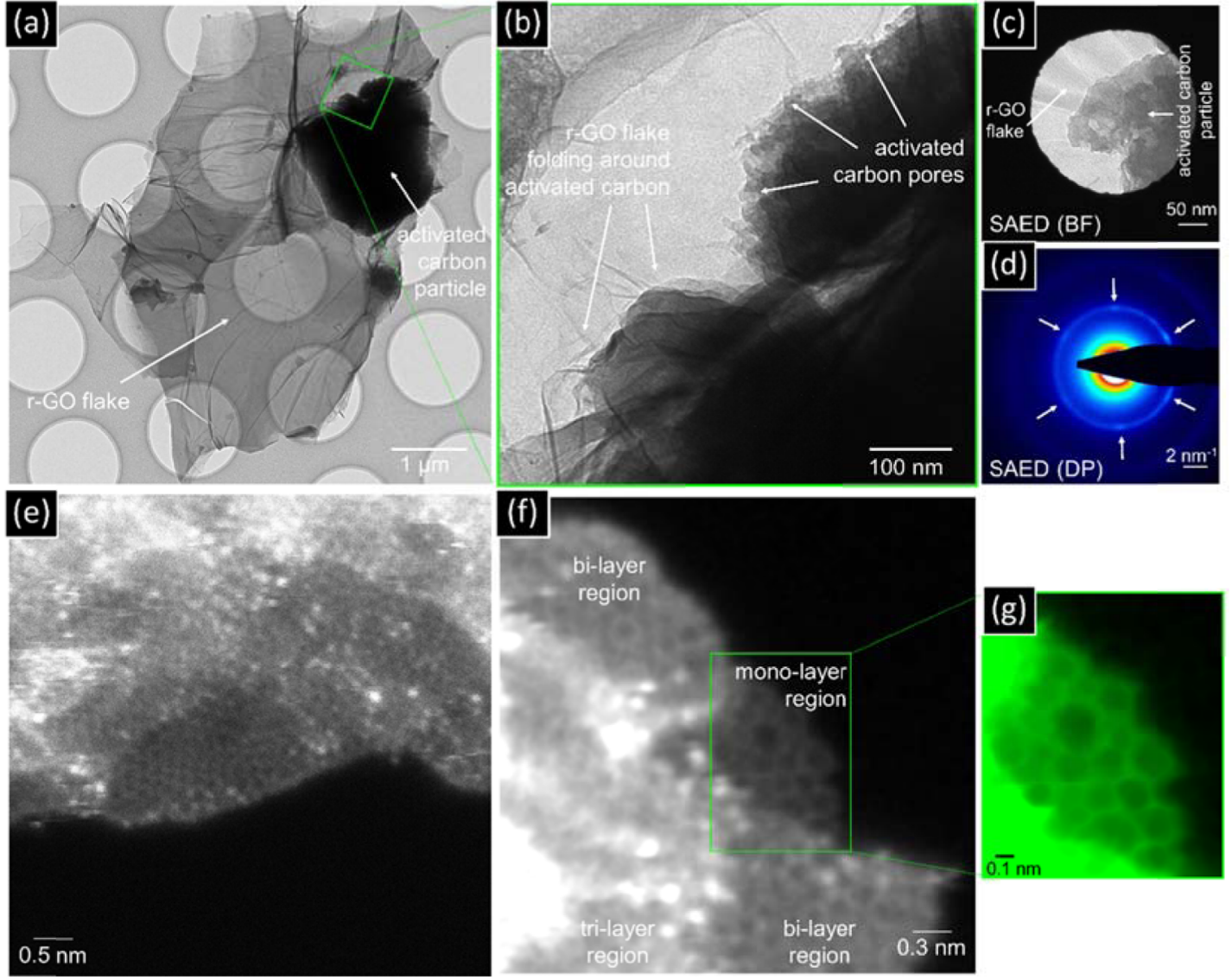

Figure 3. Bright-field TEM images ( $a, b, c)$ and SAED pattern (d) of AC/r-GO composite. The bright field image corresponding to the SAED pattern in (d) is given in (c). Annular dark field detector STEM images (e, f) of r-GO layers in the AC/r-GO composite. The blow-up (g) of the monolayer region in (f) has been Gaussian blurred and medium filtered.

composite is characterized using different complementary methods in the following paragraphs.

Scanning electron microscopy (SEM) images of the AC/rGO composite electrodes indicate a good homogeneity of the $\mathrm{AC} / \mathrm{r}-\mathrm{GO}$ composite surface on a micrometer scale (Figure 2a,b). At higher magnification (Figure 2c), a composite structure of particulate features that are wrapped by sheets of partly electron transparent material is observed. The particulate features are ascribed to the AC particles and the wrapping sheets to the r-GO. It is important to note that hardly any unwrapped AC particles are observed on the electrode surface, suggesting a good interconnection of the AC grains with the $\mathrm{r}-\mathrm{GO}$ sheets. The absence of charging during the SEM imaging indicates that the network of $\mathrm{AC} / \mathrm{r}-\mathrm{GO}$ is electrically conductive. Both observations are consistent with the good electrochemical performance of the $\mathrm{AC} / \mathrm{r}-\mathrm{GO}$ composites.
To confirm the intimate contact of $\mathrm{AC}$ and $\mathrm{r}-\mathrm{GO}$ in the electrode, the morphological and structural features of the $\mathrm{AC} /$ r-GO composite were further examined using (scanning) transmission electron microscopy ((S)TEM). For this purpose, a as-fabricated electrode (from a working electrode batch) was scratched off the $\mathrm{Al}$ current collector and the resulting material was deposited onto amorphous carbon TEM grids with regular hole arrays. TEM images at intermediate magnifications of the thus-obtained specimen (Figure 3a,b) show an isolated AC particle, which is covered by an r-GO sheet. The edges of the AC particle present the typical highly porous structure of $\mathrm{AC}^{38-40}$ (Figure $3 \mathrm{~b}$ ) and the r-GO sheet is seen to intimately fold around the AC particle, consistent with the SEM results. The selected area electron diffraction (SAED) pattern in (Figure 3c,d) correspondingly indicates two superimposed phases with graphitic structure: ${ }^{41}$ one phase with higher graphitization and a partial in-plane orientation (hexagonal 

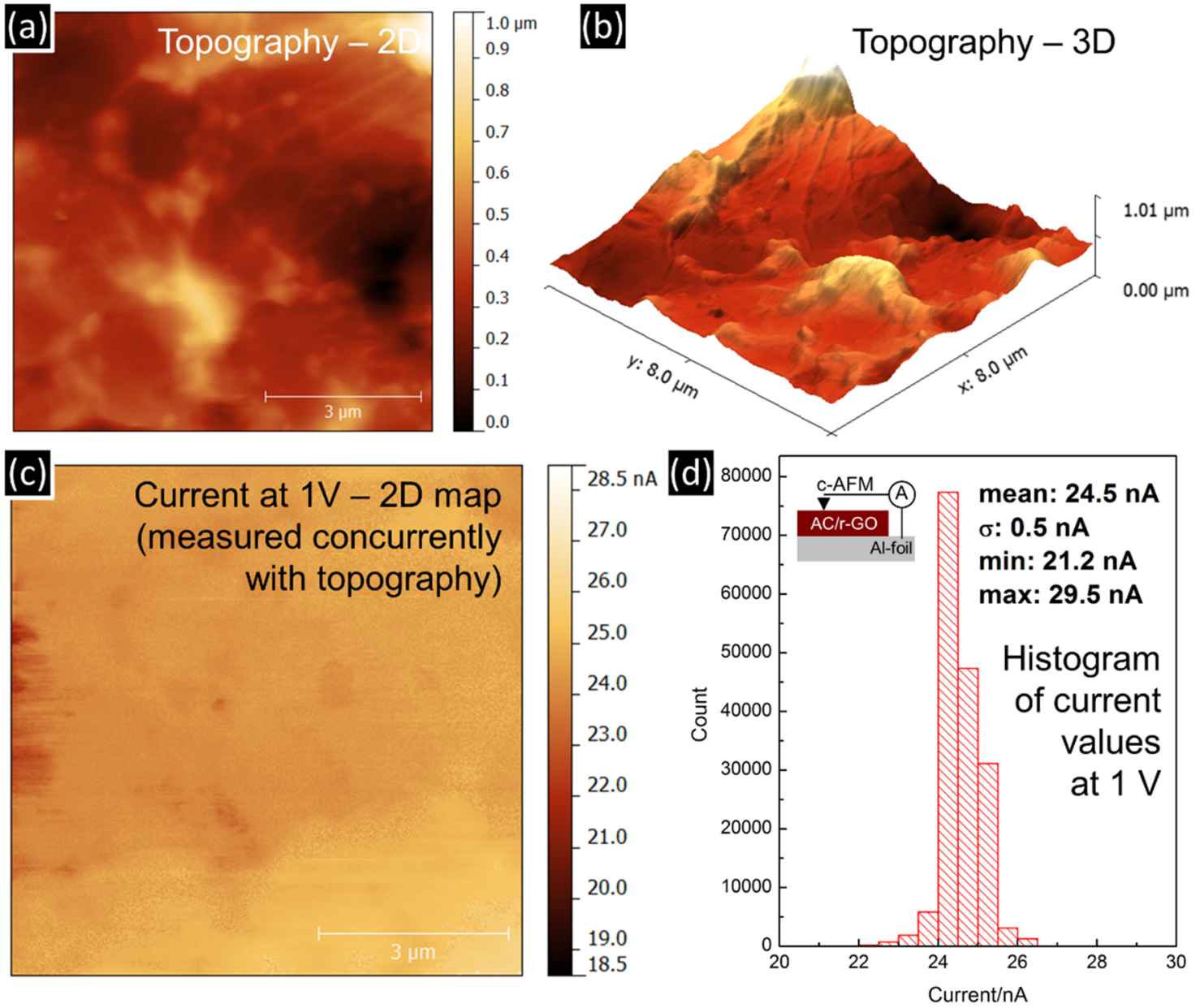

Figure 4. Topography and electrical conductivity analysis of AC/r-GO using c-AFM. (a) Two- (2D) and (b) three-dimensionally (3D) plotted contact-mode topographic AFM data of an AC/r-GO composite electrode. (c) The simultaneously recorded current map over the region in ( $a, b)$, obtained using a $1 \mathrm{~V}$ sample bias. (d) Histogram over the current values in (c). The inset shows the c-AFM measurement geometry. We note here however that c-AFM probes the electrodes in a dry state and not under electrochemical conditions ${ }^{44}$ and can thus only assess the electrodes' conductivity in a semiquantitative manner, but it cannot elucidate the electrochemical transfer resistances and transport mechanisms relevant for a working supercapacitor device.

spot pattern, white arrows), which we ascribe to the r-GO sheet, as well as another phase with lower graphitization and random orientation of nanocrystallites (rings in pattern), which is ascribed to the AC particle.

Aberration-corrected STEM elucidates the structure of the $\mathrm{r}-$ GO sheets with atomic resolution. In the STEM images (Figure 3e,f), r-GO flakes are found to be typically comprised of few layers of r-GO that are partly turbostratically restacked. Monolayer r-GO regions generally show a hexagonal "honeycomb" lattice, albeit with extensive disorder (Figure 3g), which is fully consistent with previous reports on the atomic structure of r-GO. ${ }^{42,43}$ Successful formation of $\mathrm{r}-\mathrm{GO}$ in the composite from the GO precursor is further confirmed by X-ray diffractometry (XRD) measurements and Fourier-transform infrared (FTIR) spectroscopy measurement of the $\mathrm{AC} / \mathrm{r}-\mathrm{GO}$ composites and its individual components (Supporting Information Figures 3 and 4).

Conductive tip atomic force microscopy (c-AFM) was used to further evaluate the topography of the $\mathrm{AC} / \mathrm{r}$-GO composite and the homogeneity of its electrical conductivity. ${ }^{45-47}$ Topography AFM images (two-dimensional (2D) and threedimensional (3D)) (plots) and the corresponding c-AFM current maps of an as-fabricated $\mathrm{AC} / \mathrm{r}-\mathrm{GO}$ electrode are shown in Figure 4. The observed topography of the $\mathrm{AC} / \mathrm{r}-\mathrm{GO}$ composite (Figure $4 \mathrm{a}, \mathrm{b}$ ) is found to be in good agreement with the SEM observations above (Figure 2). Global height variations on a low-micrometer scale are found with smaller local variations in the nanometer range. The latter are ascribed to the wrinkling of $\mathrm{r}-\mathrm{GO}$ sheets and AC particle protrusions. Importantly, the current map (at $1 \mathrm{~V}$ bias) in Figure $4 \mathrm{c}$ indicates a homogeneous electrical conductivity of the $\mathrm{AC} / \mathrm{r}$ GO composite over micrometer lateral length scales, which are consistent with measurements over several AC grains. In particular, no regions with significantly reduced electrical conductivity are observed. This suggests that the r-GO binder successfully electrically connects the individual AC particles and prevents particle isolation. The very small spread in the histogram over the measured current values (Figure 4d) further confirms this. Consistent with electrochemical characterization and the electron microscopy data above, the $\mathrm{AC} / \mathrm{r}-\mathrm{GO}$ electrodes are thus found to be homogeneously electrically conductive and $\mathrm{r}-\mathrm{GO}$ is thereby identified as an efficient conductive binder material for AC. 


\section{DISCUSSION}

In addressing the shortcomings related to conventional binder systems in supercapacitors, we introduced $\mathrm{r}-\mathrm{GO}$ as a monolithic multifunctional conductive binder that can replace the conventional dual-component binder system in facile, solution-based electrode coating or printing (on to current collector) process to realize large-scale and low-cost EDLCs. The near-rectangular CV curves of the $\mathrm{AC} / \mathrm{r}-\mathrm{GO}$ electrodes, even at an ultrafast scan rate of $1500 \mathrm{mV} / \mathrm{s}$, linear voltagetime profile, and the highly symmetric charge-discharge characteristics indicate a fast charge propagation and an efficient EDL formation within the AC/r-GO structure. This high-power capability along with excellent cycling stability clearly highlights the superior supercapacitive performance of the AC/r-GO electrodes. Energy density and power density of supercapacitors are also important parameters for their real-life applications. ${ }^{1}$ For our devices with $\mathrm{AC} / \mathrm{r}-\mathrm{GO}$ as the electrodes, in the $\mathrm{TEABF}_{4} / \mathrm{PC}$ electrolyte system, a power density of about $134 \mathrm{~kW} / \mathrm{kg}$ was achieved with an energy density of 17 $\mathrm{Wh} / \mathrm{kg}$ (specific capacitance of $76 \mathrm{~F} / \mathrm{g}$ ) at the current density of $5 \mathrm{~A} / \mathrm{g}$ (see the Supporting Information for calculations). Under the same conditions, AC/CMC gave a power density of $21 \mathrm{~kW} / \mathrm{kg}$ and an energy density of $11 \mathrm{Wh} / \mathrm{kg}$ (specific capacitance of $49 \mathrm{~F} / \mathrm{g}$ ), whereas those for $\mathrm{AC} / \mathrm{CMC} / \mathrm{CB}$ were $33 \mathrm{~kW} / \mathrm{kg}$ and $13 \mathrm{Wh} / \mathrm{kg}$ (specific capacitance of $58 \mathrm{~F} / \mathrm{g}$ ). Whereas the power density of comparative supercapacitors, $\mathrm{AC} / \mathrm{CMC}$ and $\mathrm{AC} / \mathrm{CMC} / \mathrm{CB}$, remains close to the range for normal AC supercapacitors with conventional binder systems $^{26,29,48}(5-20 \mathrm{~kW} / \mathrm{kg})$, that of $\mathrm{AC} / \mathrm{r}-\mathrm{GO}$ devices is far beyond this range.

To further compare these values with the literature data for monoblock electrodes (Figure 5) such as self-standing thin

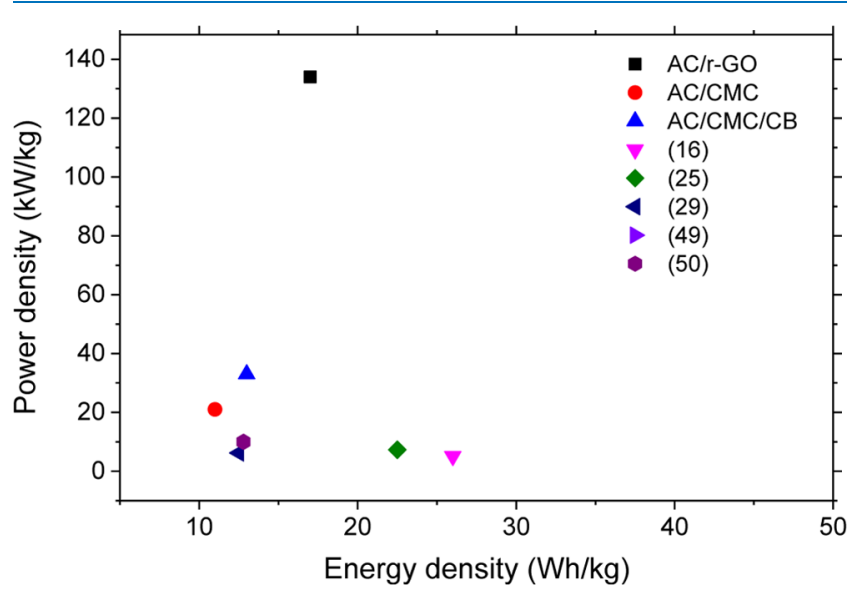

Figure 5. Performance comparison of various supercapacitors monoblock electrodes and electrodes with conventional binders with the $\mathrm{AC} / \mathrm{r}-\mathrm{GO}$ composite electrodes. Each number corresponds to the reference from which the data on power and energy density were extracted. Data of this work were obtained from $\mathrm{AC} / \mathrm{r}-\mathrm{GO}$ supercapacitor and comparative supercapacitors, $\mathrm{AC} / \mathrm{CMC}$ and $\mathrm{AC} /$ $\mathrm{CMC} / \mathrm{CB}$, in $\mathrm{TEABF}_{4} / \mathrm{PC}$ electrolyte solution.

films and aerogels developed with the purpose of overcoming the drawbacks of conventional binders, the power density of our $\mathrm{AC} / \mathrm{r}-\mathrm{GO}$ supercapacitors is much higher than the maximum power density of $5.1 \mathrm{~kW} / \mathrm{kg}$ reported for a graphene paper electrode pillared by carbon black nanoparticles in aqueous electrolyte, ${ }^{16}$ the power density of $7.3 \mathrm{~kW} / \mathrm{kg}$ for AC/ carbon nanotube paper electrode in aqueous electrolyte, ${ }^{26}$ and that of $6.2 \mathrm{~kW} / \mathrm{kg}$ obtained for composite organogels of $\mathrm{r}-\mathrm{GO}$ and $\mathrm{AC}$ in organic electrolyte of $\mathrm{TEABF}_{4} / \mathrm{PC}^{29}$ Moreover, we compare the power density of $\mathrm{AC} / \mathrm{r}-\mathrm{GO}$ devices with that of other composite electrodes based on carbon spheres and $\mathrm{r}-\mathrm{GO}$ prepared using conventional binders (Figure 5). Power densities of $4.2,10$, and $15.4 \mathrm{~kW} / \mathrm{kg}$ have been reported for 3D hierarchical composite electrode of slightly crumpled r-GO sheets intercalated with mesoporous carbon spheres (prepared using PTFE) in an aqueous electrolyte, ${ }^{49}$ for an electrode of $r$ $\mathrm{GO} / \mathrm{AC}$ (prepared using PTFE) in ionic liquid electrolyte, ${ }^{50}$ and a nanostructured electrode comprising functionalized carbon spheres and r-GO sheets (prepared using PTFE) in aqueous electrolyte, respectively, ${ }^{51}$ again confirming the highpower delivery of the $\mathrm{AC} / \mathrm{r}-\mathrm{GO}$ electrodes.

The excellent electrochemical performance of our $\mathrm{AC} / \mathrm{r}-\mathrm{GO}$ electrodes stems from the role $\mathrm{r}-\mathrm{GO}$ plays within the composite as well as the highly interconnected 3D structure that favors fast charge transportation of the electrode layer. In general, this is shown schematically in Figure 6.

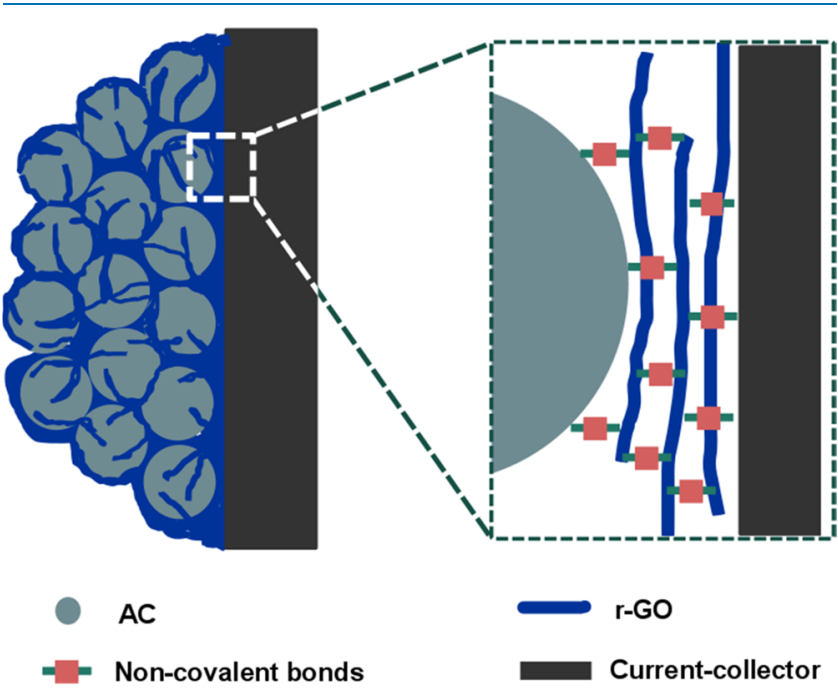

Figure 6. Schematic illustration of the AC/r-GO electrode.

r-GO is well-known for its outstanding electrical conductivity and high surface area for ion adsorption. ${ }^{52,53}$ When processed properly, these useful properties can be harnessed and such a structure provides many benefits for the improvement of energy storage applications. Within the AC/ r-GO composite, r-GO has several critical functions for efficient use of $\mathrm{AC}$ for energy storage; $\mathrm{r}-\mathrm{GO}$ facilitates the mechanical connection among AC particles in the electrode, serves to enable the mechanical integrity of electrode layer and its adhesion to the current collector and provides additional surface for EDL ion adsorption, and finally/hence replaces the need for conductive additives by improving the electrical conductivity of the composite.

Comprehensive materials characterization of our $\mathrm{AC} / \mathrm{r}-\mathrm{GO}$ electrodes clearly highlights the highly interconnected 3D structure of the composite. The r-GO layers are capable of surface contact with AC particles with low contact resistance, as shown here by our combination of SEM, TEM, and c-AFM. Conductive r-GO layers that wrap around AC particles threedimensionally not only provide additional electron transport pathways but also decrease the ion diffusion length that favors fast charge transportation resulting in high rate performance. 
Furthermore, holes created on the r-GO sheets due to the removal of in-plane $\mathrm{C}$ atoms during the reduction process may provide cross-plane diffusion channels for electrolyte ions. ${ }^{54,55}$ Functioning as the ion diffusion shortcuts between different layers of graphene, they greatly speed up the ion transport across the entire electrode film. In sharp contrast, in conventional binder systems, nonconductive polymers and conductive carbon particles that make electrical connection through a percolating point-to-point contact cause greatly retarded mass transfer and thereby place limitations on the high-power performance of EDLCs. (As a result, the CV curves of such electrodes distort with increasing sweep rate, as also seen here for the conventional $\mathrm{r}-\mathrm{GO}$-free comparative supercapacitors.)

Functional groups remaining on the r-GO layers after reducing at $300{ }^{\circ} \mathrm{C}$, such as carbonyls, ethers, and phenols, ${ }^{56,57}$ play a key role in determining the adhesive properties of $\mathrm{r}-\mathrm{GO}$ as the layers make surface contact with $\mathrm{AC}$ particles and the current collector (Supporting Information Figure 4). The noncovalent interactions (such as hydrogen bonding and $\pi-\pi$ interactions), which are established between r-GO layers themselves, and between $\mathrm{r}-\mathrm{GO}$ and $\mathrm{AC}$ particles and current collector, assist r-GO to maintain the structural stability of the electrode as the binder material, by keeping the AC particles bound together on to the current collector. This is consistent with the reports that polymers with high adhesive properties, such as alginate and poly(acrylic acid), form strong hydrogen bonds with the oxide surface on the active materials. ${ }^{58}$ Also, incorporation of such noncovalent interactions is expected to be a useful tool in tuning network properties between binder polymers and active particles. ${ }^{59,60}$ Additionally, they have been seen to improve the cycling stability of the electrodes. ${ }^{58}$ Moreover, these functional groups are also beneficial to the superior supercapacitive performances by improving electrolyte wettability and electrical conductivity. ${ }^{61}$ The unique combination of adhesive, conductive, and high surface area properties of $\mathrm{r}$-GO into a single electrode results in excellent electrochemical performance for $\mathrm{AC} / \mathrm{r}-\mathrm{GO}$ supercapacitors.

In addition, from the perspective of the electrode fabrication process, the initial GO precursor, which is present in the electrode slurry, functions as an effective dispersant for $\mathrm{AC}$ in $\mathrm{PC}$, resulting in a stable electrode material slurry that facilitates the electrode film fabrication. We find that the AC/GO slurry in PC can be applied to a collector uniformly so as to form a smooth layer on the collector, which contains the active substance in a uniform composition. This is consistent with previous reports on $\mathrm{GO}$ as an excellent two-dimensional polymeric dispersing agent for dispersion of various carbonbased materials. ${ }^{62-64}$

\section{CONCLUSIONS}

Development of an efficient binder system is a frequently overlooked bottleneck in realizing high-performance supercapacitors. In conventional methods of electrode fabrication, dual-component conductive additive-polymer binder system is added to improve the electrode stability at the expense of electrical conductivity and capacitance/weight ratio of the electrode. Therefore, a binder material that combines mechanical stability, high electrical conductivity, and significant ion-adsorption capability and can also disperse the active materials and stabilize them during solution-based electrode fabrication is urgently needed. This study reported the use of $r$ $\mathrm{GO}$ as such an ideal binder for AC-based high-power supercapacitor electrodes. With its adhesive and conductive properties and high surface area, r-GO serves as a singlecomponent conductive binder with multifunctionality to maintain high electronic conductivity and mechanical adhesion while functioning as an electrochemically active material for charge storage. Its electrochemical properties were demonstrated by the outstanding performance of the $\mathrm{AC} / \mathrm{r}-\mathrm{GO}$ composite electrodes prepared without any additional polymer binders or conductive additives. The specific capacitance of the $\mathrm{AC} / \mathrm{r}-\mathrm{GO}$ electrodes increased by $\sim 20-38 \%$ at $2 \mathrm{~A} / \mathrm{g}$ compared to comparative supercapacitors, with power density values as high as $134 \mathrm{~kW} / \mathrm{kg}$ at $5 \mathrm{~A} / \mathrm{g}$. These $\mathrm{AC} / \mathrm{r}-\mathrm{GO}$ composite electrodes exhibit excellent cycling performance with $80 \%$ capacitance retention over 20000 charge-discharge cycles. SEM, TEM, STEM observations, and c-AFM measurements together demonstrate structurally and electrically interconnected and homogeneous "wrap around" structure of $\mathrm{AC} / \mathrm{r}-\mathrm{GO}$ composites, linking the superior electrochemical performance to the microstructure of the $\mathrm{AC} / \mathrm{r}-\mathrm{GO}$ composites. The initial GO precursor, which is present in the electrode slurry, also functions as an effective dispersant for $\mathrm{AC}$, resulting in stable electrode material slurry during solution-based electrode fabrication. Importantly, such a facile solution-based process combined with electrode coating or printing on to current collector provides a practical route for making large-scale and low-cost devices. ${ }^{65}$ This combination of unique properties makes the reported monolithic multifunctional r-GO binder suitable for significantly enhancing the power capacity of industrial-type AC supercapacitors used in applications such as electric vehicles.

\section{EXPERIMENTAL SECTION}

Fabrication of AC/r-GO Electrodes and Supercapacitors. Graphene oxide (GO), synthesized using graphite oxide derived from vein graphite (purity $>99 \%$, Bogala Graphite, Sri Lanka) following Hummers' method, ${ }^{33}$ is used as the starting material of the reduced graphene oxide (r-GO), which serves as the multifunctional binder and conductive additive in the electrode composite. The as-synthesized graphite oxide was washed with a diluted $\mathrm{HCl}$ solution to completely remove residual salts. It was further washed with water until the $\mathrm{pH}$ of the rinse water became neutral $(\mathrm{pH}=7)$. Ultrapure Milli-Q water was used in all the experiments. The as-purified graphite oxide suspensions were then dispersed in water. The exfoliation of graphite oxide to GO was achieved by ultrasonication of the dispersion. Graphene oxide dispersions prepared according to the above procedure were dried in an oven maintained at a temperature of $50{ }^{\circ} \mathrm{C}$. Completely dried GO was used for further characterization and supercapacitor electrode fabrication. As produced, completely dried GO was characterized using different complementary methods ${ }^{2}$ and used for activated carbon (AC)/r-GO electrode fabrication. The results clearly confirmed the successful fabrication of GO decorated with hydroxyl, carbonyl, ether, and carboxyl groups, which in its restacked dried form keeps an interlayer distance of $\sim 0.79 \mathrm{~nm}$.

A commercially available, supercapacitor grade, steamactivated, coconut shell AC (YP-50F from Kuraray Carbons, surface area in the range of $1500-1800 \mathrm{~m}^{2} / \mathrm{g}$, pore volume 0.7 $\mathrm{cm}^{3} / \mathrm{g}$ and ash content $<1 \%$ ) was used as received without further processing to prepare the composite.

For supercapacitor electrode fabrication, GO and AC were mixed in propylene carbonate (PC) (Sigma-Aldrich, 99.7\%) to 
prepare a slurry. The investigated ratios by weight of GO to AC were 10:1, 1:1, 1:10, and 1:20, where the best supercapacitor performance was observed for $1: 10$. The mixed solution was sonicated for further dispersion of GO and the electrodes were prepared by slurry casting onto conductive coated $\mathrm{Al}$ current collector. The AC/GO composite coated on the current collector was heated at 300 ${ }^{\circ} \mathrm{C}$ in an inert $(\mathrm{Ar})$ atmosphere, at low pressure $(1 \mathrm{kPa})$ for 30 min to convert the GO within the composite electrode material into r-GO. Electrodes from GO/AC mixtures of 10:1, $1: 1$, and 1:10 were structurally stable after electrode fabrication and reduction. For 1:20, the binding between current collector and the electrode layer and binding between AC particles were poor.

Fabrication of Comparative Supercapacitors. Comparative supercapacitors were fabricated in a manner similar to that of the above-described test supercapacitor with $\mathrm{AC} / \mathrm{r}-\mathrm{GO}$ composite electrodes (referred as $\mathrm{AC} / \mathrm{r}-\mathrm{GO}$ supercapacitor).

For comparison, the following supercapacitors electrodes were fabricated:

1. Electrodes having an electrode material layer composed of the AC and sodium carboxy methyl cellulose (CMC, Sigma-Aldrich, average molecular weight $\left(M_{\mathrm{w}}\right) \sim 90$ 000), which is a conventional binder, instead of r-GO obtained by reducing GO (referred as $\mathrm{AC} / \mathrm{CMC}$ supercapacitor), with the weight ratio of $\mathrm{CMC} / \mathrm{AC}=$ $1: 10$.

2. Electrodes having an electrode material layer composed of the AC and sodium carboxy methyl cellulose (CMC) and carbon black ( $\mathrm{CB}$, Cabot Corporation), which is a conventional conductive additive, instead of $\mathrm{r}-\mathrm{GO}$ obtained by reducing $\mathrm{GO}$ (referred as $\mathrm{AC} / \mathrm{CMC} / \mathrm{CB}$ supercapacitor), with weight ratio of $\mathrm{CB} / \mathrm{CMC} / \mathrm{AC}=$ $1: 1: 10$.

3. Electrodes having an electrode material layer composed only of r-GO obtained by reducing GO under the same reduction conditions used for the reduction of $\mathrm{GO}$ in the $\mathrm{AC} / \mathrm{GO}$ composite (referred as r-GO supercapacitor).

Materials Characterization. The structure of $\mathrm{AC} / \mathrm{r}-\mathrm{GO}$ composite was characterized by field-emission scanning electron microscopy (SEM, Hitachi S-5500), conductive tip atomic force microscopy (c-AFM, NT-MDT NTEGRA Spectra $^{66}$ with NT-MDT DCP 20 tips, measured in contact mode), transmission electron microscopy (TEM, Philips CM200 at $200 \mathrm{kV}$, bright field TEM and selected area electron diffraction (SAED)), and scanning transmission electron microscopy (STEM, aberration-corrected Nion UltraSTEM 100 at $60 \mathrm{kV}$, medium angle annular dark field imaging). For TEM and STEM, the examined material was obtained directly from an as-fabricated $\mathrm{AC} / \mathrm{r}-\mathrm{GO}$ composite electrode coated on $\mathrm{Al}$ foil (from a working electrode batch). The composite was manually scratched off the $\mathrm{Al}$ foil and the thus-obtained material was dispersed in isopropyl alcohol, and then via drop cast transferred to TEM grids (Quantifoil holey amorphous carbon). For SEM, the electrode was used as it is without any further processing.

Electrochemical Testing. The electrochemical behavior of the as-prepared composite electrodes was characterized by cyclic voltammetry (CV), galvanostatic charge-discharge measurements, and electrochemical impedance spectroscopy (EIS) with two symmetric electrodes in coin cell geometry using an Autolab electrochemical interface instrument (PGSTAT $302 \mathrm{~N}$ ). A solution of $1 \mathrm{M} \mathrm{TEABF}_{4}$ (Sigma) in PC (Sigma) was used as the electrolyte and a filter paper (Whatman, grade no. 1) was used as the separator. The coin cell preparation was carried out in a nitrogen-filled glovebox (MBraun) with oxygen and moisture levels of $<1 \mathrm{ppm}$. The electrochemical measurements were taken using a twoelectrode system at ambient temperature.

Galvanostatic charge-discharge cycling was conducted between the potential limits of 0 to $+2.5 \mathrm{~V}$ at different current densities $(2,3,4$, and $5 \mathrm{~A} / \mathrm{g})$ based on the total mass of active materials. The cell capacitance at different current densities was calculated according to $C=I /(\Delta v / \Delta t)$, where $C$ is the measured capacitance for the two-electrode cell $(\mathrm{F}), I$ is the constant discharging current (A), $\Delta v$ is the voltage difference from 90 to $30 \%$ of the discharge voltage range $(\mathrm{V})$, and $\Delta t$ is the time required to go from 90 to $30 \%$ of the discharge voltage range $(s){ }^{67}$

The CV curves were recorded in the potential range from -2.5 to $+2.5 \mathrm{~V}$ at different scan rates $(50,100,200,300,400$, $500,600,700,800,900,1000$, and $1500 \mathrm{mV} / \mathrm{s})$. The cell capacitance at different scan rates was calculated according to the equation $\mathrm{C}=\left(\int \mathrm{Id} V\right) / v V$, where $C$ is the cell capacitance (F), $I$ is the response current, $V$ is the potential window, and $v$ is the $\mathrm{CV}$ scan rate $(\mathrm{mV} / \mathrm{s}){ }^{67}$

The specific capacitances were calculated from the following equation. ${ }^{67}$

$$
C_{\mathrm{sp}}(\mathrm{F} / \mathrm{g})=4 \times \mathrm{C} / \mathrm{m}
$$

Specific capacitance $C_{\mathrm{sp}}$ is the capacitance per unit mass for one electrode, where $C$ is the measured capacitance for the two-electrode cell (F) and $m$ is the total mass of the active material $(\mathrm{g})$ in both electrodes. The multiplier of 4 adjusts the capacitance of the cell and the combined mass of two electrodes to the capacitance and mass of a single electrode.

Frequency response analysis was carried out in the range of $0.01-100000 \mathrm{~Hz}$ with a DC bias of $10 \mathrm{mV}$. Extrapolating the curve on the Nyquist plot to intersect the $X$-axis yields ESR values. $^{67}$

The power density of the AC/r-GO device was calculated from the galvanostatic charge-discharge curves at different charge-discharge current densities using the following formula $^{17}$

$$
P=(\Delta V)^{2} / 4 R_{\mathrm{ESR}} m
$$

where $P$ is the power density $(\mathrm{kW} / \mathrm{kg}), \Delta V$ is the operating voltage window, and $m$ is the total mass of the active material in both electrodes. $R_{\mathrm{ESR}}$ is the internal resistance of the device estimated from the voltage drop (IR drop) at the beginning of the discharge curve and calculated from the change in voltage $\left(V_{\text {drop }}\right)$ divided by the total change in the current applied ${ }^{67}$ using the formula

$$
R_{\mathrm{ESR}}=V_{\mathrm{drop}} / 2 I
$$

The energy density of the device was obtained from the following formula ${ }^{17}$

$$
E=C_{\mathrm{sp}} \times(\Delta V)^{2} /(2 \times 3600)
$$

where $E$ is the energy density $(\mathrm{Wh} / \mathrm{kg}), C_{\mathrm{sp}}$ is the specific capacitance $(\mathrm{F} / \mathrm{g})$, and $\Delta V$ is the operating voltage window. 
The energy density $(E)$ can also be obtained by measuring the discharge time at a certain current density and calculated according to the following equation. ${ }^{68}$

$$
E=\int_{t 1}^{t 2} I V \mathrm{~d} t
$$

\section{ASSOCIATED CONTENT}

\section{S Supporting Information}

The Supporting Information is available free of charge on the ACS Publications website at DOI: 10.1021/acsomega.8b01075.

Cyclic voltammograms and Nyquist plots for the r-GO supercapacitor (Figure 1); CV profiles and dependence of the capacitive current on the applied scan rates between 50 and $1500 \mathrm{mV} / \mathrm{s}$ for the $\mathrm{AC} / \mathrm{r}-\mathrm{GO}$ supercapacitor (Figure 2); XRD patterns of r-GO, $\mathrm{AC} / \mathrm{r}-\mathrm{GO}$ composite and AC (Figure 3); FTIR spectra of $\mathrm{GO}, \mathrm{r}-\mathrm{GO}, \mathrm{AC} / \mathrm{r}-\mathrm{GO}$, and AC (Figure 4) (PDF)

\section{AUTHOR INFORMATION}

\section{Corresponding Author}

*E-mail: dtlg2@cam.ac.uk.

\section{ORCID}

Dona T. L. Galhena: 0000-0002-8619-164X

Bernhard C. Bayer: 0000-0002-4829-3207

Jannik C. Meyer: 0000-0003-4023-0778

Stephan Hofmann: 0000-0001-6375-1459

Gehan A. J. Amaratunga: 0000-0002-8614-2864

\section{Author Contributions}

D.T.L.G. synthesized graphene oxide, prepared supercapacitor cells, performed electrochemical experiments, SEM, XRD, and FTIR characterization, and analyzed the data. B.C.B and J.C.M. performed (S)TEM and AFM characterization. S.H. and G.A.J.A. supervised the project. D.T.L.G. and B.C.B. wrote the article. All the authors discussed the results and commented on the manuscript.

\section{Notes}

The authors declare no competing financial interest.

The authors declare that the data supporting the findings of this study are available within the article and its Supporting Information files.

\section{ACKNOWLEDGMENTS}

D.T.L.G. acknowledges the technical support by J. N. R. Grundy (University of Cambridge) and A. Osborne (Metrohm U.K.) and financial support from Newnham College, Cambridge, and the Cambridge Commonwealth Trust. B.C.B. acknowledges funding from the European Union's Horizon 2020 research and innovation program under the Marie Skłodowska-Curie grant agreement 656214-2DInterFOX. J.C.M. acknowledges support from the Austrian Science Fund (FWF, P25721-N20).

\section{REFERENCES}

(1) Conway, B. E. Electrochemical Capacitors: Scientific Fundamentals and Technological Applications; Kluwer Academic/Plentium Publishers, 1999.

(2) Galhena, D. T. L.; Bayer, B. C.; Hofmann, S.; Amaratunga, G. A. J. Understanding Capacitance Variation in Sub-Nanometer Pores by
In-Situ Tuning of Interlayer Constrictions. ACS Nano 2016, 10, 747754.

(3) Forse, A. C.; Merlet, C.; Griffin, J. M.; Grey, C. P. New Perspectives on the Charging Mechanisms of Supercapacitors. J. Am. Chem. Soc. 2016, 138, 5731-5744.

(4) Prehal, C.; et al. Tracking the structural arrangement of ions in carbon supercapacitor nanopores using in situ small-angle X-ray scattering. Energy Environ. Sci. 2015, 8, 1725-1735.

(5) Simon, P.; Gogotsi, Y. Materials for electrochemical capacitors. Nat. Mater. 2008, 7, 845-854.

(6) Jurewicz, K.; et al. Capacitance properties of ordered porous carbon materials prepared by a templating procedure. J. Phys. Chem. Solids 2004, 65, 287-293.

(7) Hasegawa, G.; Kanamori, K.; Nakanishi, K.; Abe, T. New insights into the relationship between micropore properties, ionic sizes, and electric double-layer capacitance in monolithic carbon electrodes. J. Phys. Chem. C 2012, 116, 26197-26203.

(8) Kondrat, S.; Pérez, C. R.; Presser, V.; Gogotsi, Y.; Kornyshev, A. A. Effect of pore size and its dispersity on the energy storage in nanoporous supercapacitors. Energy Environ. Sci. 2012, 5, 6474-6479.

(9) Wang, S. Y.; Wu, N. L. Operating characteristics of aqueous magnetite electrochemical capacitors. J. Appl. Electrochem. 2003, 33, 345-348.

(10) Chmiola, J.; Largeot, C.; Taberna, P.-L.; Simon, P.; Gogotsi, Y. Desolvation of Ions in Subnanometer Pores and Its Effect on Capacitance and Double-Layer Theory. Angew. Chem. 2008, 120, 3440-3443.

(11) Emmenegger, C.; et al. Investigation of electrochemical doublelayer (ECDL) capacitors electrodes based on carbon nanotubes and activated carbon materials. J. Power Sources 2003, 124, 321-329.

(12) Yuan, G. H.; Jiang, Z. H.; Aramata, A.; Gao, Y. Z. Electrochemical behavior of activated-carbon capacitor material loaded with nickel oxide. Carbon 2005, 43, 2913-2917.

(13) Arbizzani, C.; Mastragostino, M.; Soavi, F. New trends in electrochemical supercapacitors. J. Power Sources 2001, 100, 164-170.

(14) Lux, S. F.; et al. Greener and Cheaper Batteries Containing Fluorine-Free Binder in Combination with Ionic Liquid Based Electrolytes. ECS Trans. 2010, 25, 21-25.

(15) Beck, F.; Dolata, M. Fluorine-free binders for carbon black based electrochemical supercapacitors. J. Appl. Electrochem. 2001, 31, $517-521$

(16) Wang, G.; et al. Flexible pillared graphene-paper electrodes for high-performance electrochemical supercapacitors. Small 2012, 8, $452-459$.

(17) El-Kady, M. F.; Strong, V.; Dubin, S.; Kaner, R. B. Laser Scribing of High-Performance and Flexible Graphene-Based Electrochemical Capacitors. Science 2012, 335, 1326-1330.

(18) Zhang, L. L.; et al. Highly conductive and porous activated reduced graphene oxide films for high-power supercapacitors. Nano Lett. 2012, 12, 1806-1812.

(19) El-Kady, M. F.; Kaner, R. B. Scalable fabrication of high-power graphene micro-supercapacitors for flexible and on-chip energy storage. Nat. Commun. 2013, 4, No. 1475.

(20) Wang, D. W.; et al. Fabrication of graphene/polyaniline composite paper via in situ anodic electropolymerization for highperformance flexible electrode. ACS Nano 2009, 3, 1745-1752.

(21) Jiang, Y.; et al. Uniformly embedded metal oxide nanoparticles in vertically aligned carbon nanotube forests as pseudocapacitor electrodes for enhanced energy storage. Nano Lett. 2013, 13, 35243530.

(22) Kaempgen, M.; Chan, C. K.; Ma, J.; Cui, Y.; Gruner, G. Printable Thin Film Supercapacitors Using Single-Walled Carbon Nanotubes. Nano Lett. 2009, 9, 1872-1876.

(23) Pushparaj, V. L.; et al. Flexible energy storage devices based on nanocomposite paper. Proc. Natl. Acad. Sci. U.S.A. 2007, 104, 1357413577.

(24) Futaba, D. N.; et al. Shape-engineerable and highly densely packed single-walled carbon nanotubes and their application as supercapacitor electrodes. Nat. Mater. 2006, 5, 987-994. 
(25) Kim, C. H. J.; Zhang, H.; Liu, J. Graphene oxide as a dualfunction conductive binder for PEEK-derived microporous carbons in high performance supercapacitors. 2D Mater. 2015, 2, No. 024006.

(26) $\mathrm{Xu}, \mathrm{G}$.; et al. Binder-free activated carbon/carbon nanotube paper electrodes for use in supercapacitors. Nano Res. 2011, 4, 870881.

(27) Mayer, S. T.; Pekala, R. W.; Kaschmitter, J. L. The Aerocapacitor: An Electrochemical Double-Layer Energy-Storage Device. J. Electrochem. Soc. 1993, 140, 446-451.

(28) Xu, Y.; et al. Flexible Solid-State Supercapacitors Based on Three-Dimensional Graphene Hydrogel Films. ACS Nano 2013, 7, 4042-4049.

(29) Zhou, Q.; Gao, J.; Li, C.; Chen, J.; Shi, G. Composite organogels of graphene and activated carbon for electrochemical capacitors. J. Mater. Chem. A 2013, 1, 9196-9201.

(30) Böckenfeld, N.; Jeong, S. S.; Winter, M.; Passerini, S.; Balducci, A. Natural, cheap and environmentally friendly binder for supercapacitors. J. Power Sources 2013, 221, 14-20.

(31) Kouchachvili, L.; Maffei, N.; Entchev, E. Novel binding material for supercapacitor electrodes. J. Solid State Electrochem. 2014, $18,2539-2547$.

(32) Alhabeb, M.; Beidaghi, M.; Aken, K. L. Van; Dyatkin, B.; Gogotsi, Y. High-density freestanding graphene/carbide-derived carbon film electrodes for electrochemical capacitors. Carbon 2017, $118,642-649$.

(33) Hummers, W. S., Jr.; Offeman, R. E. Preparation of Graphitic Oxide. J. Am. Chem. Soc. 1958, 80, No. 1339.

(34) Dreyer, D. R.; Park, S.; Bielawski, C. W.; Ruoff, R. S. The chemistry of graphene oxide. Chem. Soc. Rev. 2010, 39, 228-240.

(35) Pfaffeneder-Kmen, M.; Bausch, F.; Trettenhahn, G.; Kautek, W. In Situ FTIR and in Situ QMB Study of the Electrochemistry of Graphene Oxide on Platinum. J. Phys. Chem. C 2016, 120, 1556315568.

(36) Pandey, G. P.; et al. Mesoporous Hybrids of Reduced Graphene Oxide and Vanadium Pentoxide for Enhanced Performance in Lithium-Ion Batteries and Electrochemical Capacitors. ACS Appl. Mater. Interfaces 2016, 8, 9200-9210.

(37) Taberna, P. L.; Simon, P.; Fauvarque, J. F. Electrochemical Characteristics and Impedance Spectroscopy Studies of CarbonCarbon Supercapacitors. J. Electrochem. Soc. 2003, 150, A292-A300.

(38) Harris, P. J. F.; Liu, Z.; Suenaga, K. Imaging the atomic structure of activated carbon. J. Phys.: Condens. Matter 2008, 20, No. 362201.

(39) Pré, P.; et al. A new approach to characterize the nanostructure of activated carbons from mathematical morphology applied to high resolution transmission electron microscopy images. Carbon 2013, 52, 239-258.

(40) Han, W. Q.; Brutchey, R.; Tilley, T. D.; Zettl, A. Activated Boron Nitride Derived from Activated Carbon. Nano Lett. 2004, 4, $173-176$.

(41) Meyer, J. C.; et al. The structure of suspended graphene sheets. Nature 2007, 446, 60-63.

(42) Erickson, K.; et al. Determination of the local chemical structure of graphene oxide and reduced graphene oxide. Adv. Mater. 2010, 22, 4467-4472.

(43) Gómez-Navarro, C.; et al. Atomic structure of reduced graphene oxide. Nano Lett. 2010, 10, 1144-1148.

(44) Reiner-Rozman, C.; Schodl, J.; Nowak, C.; Kleber, C. Scanning Electrochemical Microscopy as a Characterization Tool for Reduced Graphene Oxide Field Effect Transistors. e-J. Surf. Sci. Nanotechnol. 2015, 13, 366-372.

(45) Wei, Z.; et al. Nanoscale tunable reduction of graphene oxide for graphene electronics. Science 2010, 328, 1373-1376.

(46) Ekiz, O. O.; Ürel, M.; Güner, H.; Mizrak, A. K.; Dâna, A. Reversible electrical reduction and oxidation of graphene oxide. ACS Nano 2011, 5, 2475-2482.

(47) Mativetsky, J. M.; et al. Local current mapping and patterning of reduced graphene oxide. J. Am. Chem. Soc. 2010, 132, 1413014136.
(48) Liu, C.; Yu, Z.; Neff, D.; Zhamu, A.; Jang, B. Z. GrapheneBased Supercapacitor with an Ultrahigh Energy Density. Nano Lett. 2010, 10, 4863-4868.

(49) Lei, Z.; Christov, N.; Zhao, X. S. Intercalation of mesoporous carbon spheres between reduced graphene oxide sheets for preparing high-rate supercapacitor electrodes. Energy Environ. Sci. 2011, 4, $1866-1873$

(50) Chen, Y.; et al. High-performance supercapacitors based on a graphene-activated carbon composite prepared by chemical activation. RSC Adv. 2012, 2, 7747-7753.

(51) Guo, C. X.; Li, C. M. A self-assembled hierarchical nanostructure comprising carbon spheres and graphene nanosheets for enhanced supercapacitor performance. Energy Environ. Sci. 2011, 4, 4504-4507.

(52) Stoller, M. D.; Park, S.; Zhu, Y.; An, J.; Ruoff, R. S. Graphenebased ultracapacitors. Nano Lett. 2008, 8, 3498-3502.

(53) Skákalová, V.; et al. Electronic transport in composites of graphite oxide with carbon nanotubes. Carbon 2014, 72, 224-232.

(54) Xu, Y.; et al. Solution processable holey graphene oxide and its derived macrostructures for high-performance supercapacitors. Nano Lett. 2015, 15, 4605-4610.

(55) Alsharaeh, E.; et al. Novel synthesis of holey reduced graphene oxide (HRGO) by microwave irradiation method for anode in lithium-ion batteries. Sci. Rep. 2016, 6, No. 29854.

(56) Bagri, A.; et al. Structural evolution during the reduction of chemically derived graphene oxide. Nat. Chem. 2010, 2, 581-587.

(57) Acik, M.; et al. The role of oxygen during thermal reduction of graphene oxide studied by infrared absorption spectroscopy. J. Phys. Chem. C 2011, 115, 19761-19781.

(58) Lopez, J.; et al. The effects of cross-linking in a supramolecular binder on cycle life in silicon microparticle anodes. ACS Appl. Mater. Interfaces 2016, 8, 2318-2324.

(59) Koo, B.; et al. A highly cross-linked polymeric binder for highperformance silicon negative electrodes in lithium ion batteries. Angew. Chem., Int. Ed. 2012, 51, 8762-8767.

(60) Choi, J. W.; Aurbach, D. Promise and reality of post-lithium-ion batteries with high energy densities. Nat. Rev. Mater. 2016, 1, No. 16013.

(61) Wang, Y.; et al. Supercapacitor devices based on graphene materials. J. Phys. Chem. C 2009, 113, 13103-13107.

(62) Tian, L.; et al. Graphene oxides for homogeneous dispersion of carbon nanotubes. ACS Appl. Mater. Interfaces 2010, 2, 3217-3222.

(63) Tian, L.; et al. Graphene oxides dispersing and hosting graphene sheets for unique nanocomposite materials. ACS Nano 2011, 5, 3052-3058.

(64) Li, Y.; Yang, J.; Zhao, Q.; Li, Y. Dispersing carbon-based nanomaterials in aqueous phase by graphene oxides. Langmuir 2013, 29, 13527-13534.

(65) Yu, G.; et al. Solution-processed graphene/ $\mathrm{MnO} 2$ nanostructured textiles for high-performance electrochemical capacitors. Nano Lett. 2011, 11, 2905-2911.

(66) Elibol, K.; et al. Visualising the strain distribution in suspended two-dimensional materials under local deformation. Sci. Rep. 2016, 6, No. 28485.

(67) Stoller, M. D.; Ruoff, R. S. Best practice methods for determining an electrode material's performance for ultracapacitors. Energy Environ. Sci. 2010, 3, 1294-1301.

(68) Jiang, J.; et al. A systematically comparative study on $\mathrm{LiNO}_{3}$ and $\mathrm{Li}_{2} \mathrm{SO}_{4}$ aqueous electrolytes for electrochemical double-layer capacitors. Electrochim. Acta 2018, 274, 121-130. 